\title{
BMJ Global Health National action to combat AMR: a One- Health approach to assess policy priorities in action plans
}

To cite: Ogyu A, Chan 0 , Littmann J, et al. National action to combat AMR: a OneHealth approach to assess policy priorities in action plans. BMJ Global Health 2020;5:e002427. doi:10.1136/ bmjgh-2020-002427

Handling editor Seye Abimbola

- Additional material is published online only. To view please visit the journal online (http://dx.doi.org/10.1136/ bmjgh-2020-002427).

Received 21 February 2020 Revised 19 May 2020 Accepted 23 May 2020

\section{Check for updates}

\section{Author(s) (or their} employer(s)) 2020. Re-use permitted under CC BY-NC. No commercial re-use. See rights and permissions. Published by BMJ.

${ }^{1}$ School of Public Health, Li Ka Shing Faculty of Medicine, The University of Hong Kong, Hong Kong, China

${ }^{2}$ Norwegian Institute of Public Health, Oslo, Norway

${ }^{3}$ College of Veterinary Medicine, Xinjiang Agricultural University, Ulumuqi, China

${ }^{4}$ AMR Clinical Reference Center, National Center for Global Health and Medicine, Shinjuku-ku, Japan

${ }^{5}$ Global Studies Institute, University of Geneva, Geneva, Switzerland

Correspondence to

Anju 0gyu; anjuo@hku.hk

\section{ABSTRACT}

Little is known about the overall trend and prioritisations of past and current antimicrobial resistance (AMR) policies. Here we introduce a quantitative method to analyse AMR policies. The AMR-Policy Analysis Coding Toolkit (AMRPACT) uses several categorical variables. Thirteen AMR action plans from five countries (China, Japan, Norway, the UK and the USA) were used to develop the tool and identify possible values for each variable. The scope and capability of AMR-PACT is demonstrated through the 2015 WHO's Global Action Plan and 2017 Hong Kong AMR Action Plan (HKAP). Majority of policies were aimed at either human or animal sector with less attention given to the environment, plant or food sector. Both plans shared the same two strategic focus areas, namely the conservation of antibiotics and the improved surveillance of resistance. There were no policies dedicated to improving access to antibiotics in the HKAP. These empirical results provide useful insights into the priorities and gaps of AMR policies. The method proposed here can help understand countries' priorities regarding AMR, support the creation of AMR policy database and foster innovative policymaking.

\section{INTRODUCTION}

Antimicrobial resistance (AMR) has been a health policy challenge for the past 75 years, although response have varied greatly over time, and between countries and regions. ${ }^{12}$ Recent international efforts have resulted in the adoption of a Global Action Plan (GAP) in 2015 by the WHO as the blueprint for combatting AMR. ${ }^{3}$ To tackle the multifaceted and complex challenge of AMR, the GAP makes 83 recommendations covered under five main objectives to member states, WHO Secretariat and other international and national stakeholders. As member states are the primary locus of action, the formulation and implementation of effective national policies are critical for successfully combatting AMR. Five years on, 117 countries have adapted the GAP to produce their own national action plan (NAP), ${ }^{4}$ yet, many

\section{Key questions}

What is already known?

- The WHO global database for antimicrobial resistance (AMR) country self-assessment include general information on whether policies exist in areas such as antimicrobial stewardship or regulations on distribution of antibiotics.

- To date, no detailed analyses of AMR policies and their content exists.

\section{What are the new findings?}

- This new approach to analyse AMR policy documents can be used to quantify and identify the current policy gaps which include lack of policies in the environment, plant and food sectors.

- Despite AMR being a One-Health issue, a lack of clarity exists where the language used in AMR policies is not written explicitly which may affect the variety of interpretation from actors with the role of implementation.

\section{What do the new findings imply?}

- This approach can be used in the future by policymakers to develop AMR action plans with clear and explicit language using the values identified and create specific policies based on the needs of the country rather than based entirely on the WHO's Global Action Plan.

- A creation of an AMR policy database can aid policyadvisors and policymakers to make better, informed policy recommendations with reference to action being taken in other countries that have comparable AMR challenges.

countries still face growing levels of antimicrobial consumption and AMR rates. ${ }^{56}$

With AMR receiving a growing political attention at all levels, so too have the interest in analysing effective policy measures. In 2015, Dar et $a l^{7}$ identified surveillance, infection prevention, responsible use, universal access and innovation and research and development as the main policy goals to tackle AMR. Other works regarding AMR policies have 
focused on the way the challenge is framed, ${ }^{8}$ the challenges of implementation ${ }^{9}$ and on how to better assess the governance dimension of AMR policies. ${ }^{10}$ Currently, there are growing insights about AMR policies but a lack of a comprehensive framework for the systematic analysis of AMR policies at the national level.

Policy analysis of the content of NAPs can help capture important information on policies envisaged at the formulation stage which include the areas of prioritisation, objectives, sectors and target population. An analytical framework on AMR policies is an important step to consolidate information on past and existing policies in a systematic manner, to make sense of the diversity of national action against AMR, and to relate this information to countries' situation regarding AMR. Currently, no such analytical framework exists in the literature. The goal of this paper is to introduce such a tool, which can help systematically categorise, describe and quantify useful information about AMR policies.

\section{METHODS}

An important part of health policy analysis focuses on explaining why some policies were adopted and consists of situational analyses of policies through case studies, anecdotes $^{11-13}$ or self-reported questionnaires based on established variables. ${ }^{14} 15$ For issues that are highly multidimensional and associated with a variety of policies that cross sectors, such as AMR, good description of the different components of policy formulation are often lacking, and require novel methods. ${ }^{16}$ Content analysis of policy characteristics is a step towards quantification, ${ }^{17}$ however, the coded content taken in isolation of the other parts of the text loses its meaning without its context. ${ }^{18}$ In addition, both data collection and coding can be laborious and reproducibility in coding is often low. Effort to categorise policies have also led to the creation of policy database in areas such as that of the United Nations World Population Policies Database, ${ }^{19}$ the Policy database on Employment and decent work in rural areas by the Food and Agricultural Organisation, ${ }^{20}$ or the Climate Policy Database by NewClimate. ${ }^{21}$ The main limitation of the existing methodology used within these databases comes from the way multiple values found in the same categorical variable within policy documents are aggregated thereby obfuscating the finer details of individual policies. The generated queried result also only showcases the summarised content of the policies rather than the original wording of the document. For multisectoral issue such as AMR, this matters, because it effectively removes important sector-specific details and results.

\section{An interdisciplinary framework and method for AMR policy analysis}

The use of an interdisciplinary framework that is tailored to the nature of the problem can improve coding and quantification. Drawing on the literature, we propose a consolidated conceptual and methodological 'OneHealth' $(\mathrm{OH})$ approach to the analysis of policy formulation regarding AMR which can retain both the original policy statement content and context. The AMRIntervene framework, which has been developed to provide a comprehensive assessment of AMR interventions, can provide a relevant basis for policy analysis. ${ }^{22}$ However, with its focus on intervention rather than formulated policies, an adaptation of the framework is necessary.

To adapt the framework for AMR policy analysis, the following six categorical variables were preserved: sector, target setting, target social group, goal, policy instrument and building blocks. ${ }^{22}$ For several variables (sector, goal, policy instruments), further subvariables were used to be more specific about the policy content. Drawing on the policy literature, we also identified a new categorical variable 'policy process' to describe the stage at which certain policy statements were at. ${ }^{23}$ In total, seven categorical variables make up the framework of the AMR-Policy Analysis Coding Tool (AMR-PACT). During the development of this tool, 13 documents covering the GAP and the AMR action plans (APs) of China, including Hong Kong (HK), Japan, Norway, the UK and the USA published between 2000 and 2019 were selected and coded as part of a larger project. $^{324-35}$ The values from each categorical variable were also adapted and new additions were made to the list during pilot coding to ensure detailed description of policies. The full list of variables and associated values can be found in online supplementary table 1 .

\section{Precoding: policy document search strategy and cleaning}

As the framework aims to analyse AMR-related policies, NAPs were collected from the WHO database and additional AMR APs were found on government websites. NAPs and APs consist of multiple statements, which are more or less specific and detailed. For the purpose of this article, we defined these statements (or quotes) about one specific question as a policy. The advantage of this method is to be able to categorise separately different actions formulated in the APs. To demonstrate how the tool can be applied, the WHO GAP and Hong Kong Action Plan (HKAP) were selected. For each document, we extracted their country and year of publication. Temporal dimensions are important to understand the evolution of AMR policies. For example, policy documents published around 2000 should be distinguished from NAPs published after 2015 when countries adopted the WHO GAP as a blueprint for the development of AMR policies at the national level. These data were stored within the database as metainformation about the policies. During the assessment, we identified diversity and inconsistencies in the way policies are organised within NAPs. In most cases, multiple policy statements with related themes are grouped together under an overarching section heading. As the majority of AMR NAPs follow the GAP framework, these themes usually fall under the five objectives of the GAP. To ensure that 


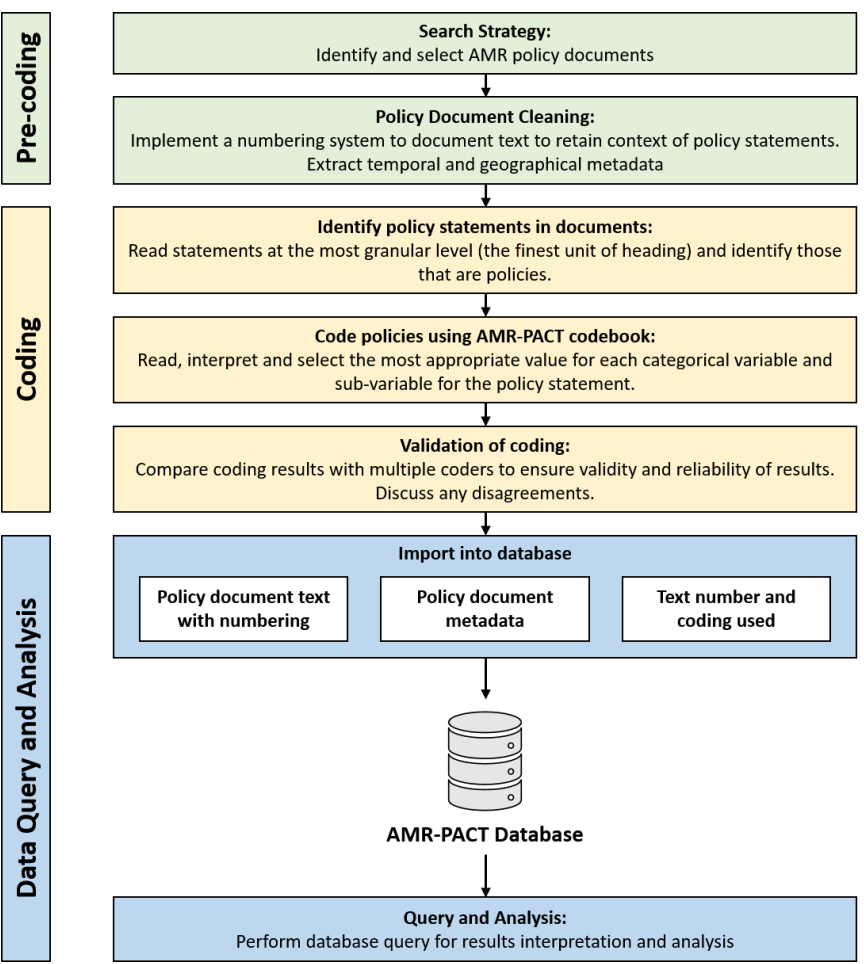

Figure 1 Steps taken in the analysis of AMR policies within policy documents. AMR, antimicrobial resistance; AMRPACT, AMR-Policy Analysis Coding Toolkit.

the details and context of the policy are captured during coding, query and analysis, preparation and cleaning of these documents were performed beforehand (figure 1). As policy statement can lose their meaning if the text is coded without considering the header, we reprocessed documents so that the full context of statements can be retained. When undergoing further qualitative analysis during database query, we assigned a hierarchical numbering system to each header and subsequent subheadings of policy statements, and then rewrote policy documents with each quote preceded by the different levels of headers (figure $2 \mathrm{~B}$ ).

\section{Coding}

Here we define the coding process as the interpretation of policy statements by the coder and the tagging of these statements using the variables of the $\mathrm{OH}$ framework. All categorical variables and the respective nonnumerical values that they can take were preassigned a unique identification number (ID), which was stored within a codebook that also generates a corresponding string ID code (figure 2A). The string code ensures that the individual values are connected to each other. This is especially useful when the policy statement can be coded using multiple values within one variable. For example, a policy statement addressing both restriction of the use of growth promoter in the animal livestock sector and conservation of antibiotics in the human health sector. Through using a string and connecting these elements, the specificity of the policy statement can be preserved thereby reducing the loss of information. This helps to transform a text that may contain various pieces of information into a more accurate representation of the priorities in NAPs. When listed values did not fully capture the content of the policy statement, the team discussed the creation of a new values. After a consensus was reached, the new value was added.

Coding was executed at the most granular level (ie, the smallest unit of the numbered heading) to enable characterisation of policy statements within their context as the different elements of the categories may be found on separate levels of the policy statement hierarchy (figure 2B). For the GAP, statements under headings 'strategic objectives' and 'Member State action' within 'framework for action on antimicrobial resistance' were coded. Within the HKAP, statements under each 'Key Area' were coded. During coding, multiple codes were necessary for some statements which had characteristics of two or more values within one categorical variable. This is illustrated in the coding of text number '1.1.1.1.' where variables sector, subsector, challenge, subchallenge and building blocks contained two or more values (table 1) resulting in the text being tagged with seven unique codes (figure 2B). The computer-assisted qualitative data analysis software Atlas.ti was used to speed up the process of coding by applying to the codes directly to the text as well as to ensure straightforward data transfer into the database. To ensure reliability, policy documents were coded by two coders, who worked separately (AO and $\mathrm{OC}$ ), and whose results were subsequently compared. To reduce interpretation bias, the coding process was limited to information that can be explicitly extracted from the document. Differences in coding were discussed among the two to reach an agreement and when agreement could not be reached, this was further discussed within the group to make the final decision. To further provide guidance to the coders, the team developed a coding guide with definitions of each value with examples of policy statements extracted from the 13 policy documents and specific instructions for when to use and when not to use in order to achieve intercoder reliability.

\section{Data query and analysis}

Once coding was completed, the data were cleaned and transferred to a Microsoft Access Database for quantitative analysis. Database query was used to generate a matrix to chart the number of policy statements coded with each value under all categorical variables. To show the relative differences between the contents and characteristics of policies within APs, the number of codes with each value was calculated as a percentage using the total number of codes in the APs. All values were listed in alphabetical order with the 'other' and 'unspecified' values placed at the end. The string code also provides the ability to explore both the granularity and specificity of policies. Granularity was defined and calculated as the number of the categorical variable and subvariables in each coding string which contained a distinct value. For each code, a score of one or null was given depending 


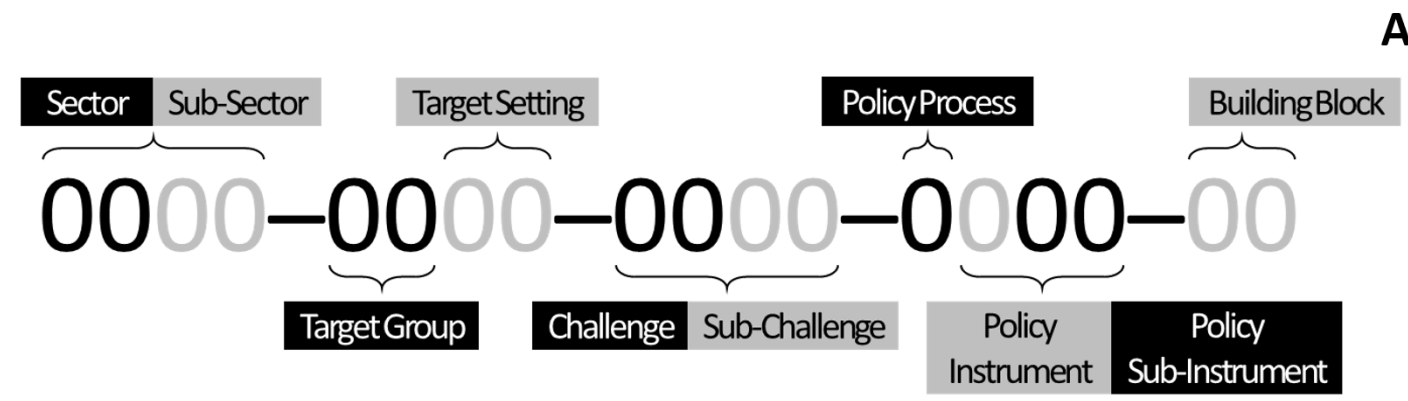

B

\begin{tabular}{|c|c|c|}
\hline \multicolumn{2}{|c|}{ Hong Kong Strategy and Action Plan on Antimicrobial Resistance (2017-2022) } & Code \\
\hline \multicolumn{3}{|c|}{ 1. Strengthen knowledge through surveillance and research } \\
\hline \multicolumn{3}{|c|}{ 1.1. Set up antimicrobial resistance surveillance system under One Health for Hong Kong } \\
\hline 1.1.1. & $\begin{array}{l}\text { Establish a coordination structure for One Health surveillance on AMR. Establish a } \\
\text { Working Group on AMR One Health Surveillance (tentative name) to steer and } \\
\text { oversee the development of surveillance on AMR and antimicrobial use: }\end{array}$ & \\
\hline & $\begin{array}{l}\text { 1.1.1.1. Form a network to gather, analyse, share and link data from multiple } \\
\text { surveillance and monitoring systems including } H A \text {, Public Health } \\
\text { Laboratory and future surveillance platforms covering food animals and } \\
\text { food. }\end{array}$ & $\begin{array}{l}0102-0000-0603-2000-06 \\
0102-0000-0606-2000-06 \\
0201-0000-0603-2000-06 \\
0201-0000-0606-2000-06 \\
0500-0000-0603-2000-06 \\
0601-0000-0603-2000-04 \\
0601-0000-0606-2000-04\end{array}$ \\
\hline & 1.1.1.2. Regularly disseminate data on $A M R$ and antimicrobial use. & $\begin{array}{l}0600-0000-0603-2000-04 \\
0600-0000-0606-2000-04\end{array}$ \\
\hline \multicolumn{3}{|c|}{ 1.1.2. $[\ldots]$} \\
\hline \multicolumn{3}{|c|}{ 1.2. Build laboratory capacity to support surveillance activities in both human and animal sectors } \\
\hline \multicolumn{3}{|c|}{$\begin{array}{l}\text { Standardise laboratory antimicrobial susceptibility testing method for AMR } \\
\text { surveillance }\end{array}$} \\
\hline & $\begin{array}{l}\text { 1.2.2.1. Form a network to gather, analyse, share and link data from multiple } \\
\text { surveillance and monitoring systems including } H A \text {, Public Health } \\
\text { Laboratory and future surveillance platforms covering food animals and } \\
\text { food. }\end{array}$ & $\begin{array}{l}0102-0000-0603-4000-00 \\
0102-0003-0603-3000-04 \\
0102-0009-0603-3000-04\end{array}$ \\
\hline
\end{tabular}

Figure 2 (A) The 22-digit coding string is used to store the coder-selected variables which best describes the content of policy statements. (B) The policy document is cleaned and given a hierarchical numbering system to ensure relationships between statements are retained within the database and during query. The smallest units of each heading are coded.

on the value. Null scores were given to the categorical variable or subvariables which contained values of 'other' or 'unspecified'. The total score out of 10 was given to each code. Codes with a score of 10 were seen as policies with the most granularity. Specificity was defined as the ability of the policy statements to provide focused policies. As AMR is a $\mathrm{OH}$ problem, a single policy statement can potentially address multiple policy areas. To quantify specificity, the number of codes per policy statement within the document was queried. A lower number represents a policy (quote) that is consice and to the point.

\section{Patient and public involvement}

This research was done without patient or public involvement.

\section{RESULTS}

\section{Global Action Plan}

In total 175 codes were applied to 59 policy statements within the GAP. The mean specificity was 2.97 , with the largest number of codes applied to a single statement being 10 . The overall mean granularity of the codes was 5.35 with the categorical variable with the most null values being the target setting and the least being the challenge of AMR. There was a single code that had a full score of 10. Among the objectives, the largest proportion of codes were found under objective $4(32.6 \%)$ and $2(30.3 \%)$ while objective 1 contained the least $(9.7 \%$, figure 3$)$.

The two most prioritised sectors were animal health $(34.3 \%)$ followed by in the human $(30.3 \%)$. However, more than half of the codes used in the animal sector did not have a specific subsector compared with policies in the human sector, where almost $80 \%$ had indicated whether the policy was aimed at either community, healthcare delivery or healthcare industry. Policies covered each of the six sectors with $24 \%$ not explicitly stating the sector being targeted. With regards to the challenges of AMR, all six were covered with conservation of antibiotics as the most frequently mentioned strategy $(33.1 \%)$, followed by surveillance $(17.1 \%)$ and innovation $(12.0 \%)$. Policies to improve access to antibiotics were least prominent $(3.4 \%)$. Overall, $12.6 \%$ of the coding did not specify 
Table 1 How selection of values for each categorical variables and subvariables was executed using text number [1.1.1.1.] from the HKAP with evidence from the text

\begin{tabular}{|c|c|c|c|}
\hline Variables and subvariables: & Prompting question & Selected value (ID) & Evidence from text [1.] to [1.1.1.1.] \\
\hline \multirow{2}{*}{$\begin{array}{l}\text { Sector and } \\
\text { subsector }\end{array}$} & \multirow{2}{*}{$\begin{array}{l}\text { Which sector (or area of } \\
\text { interest) is the policy aimed } \\
\text { at? If stated, is there a specific } \\
\text { area within that sector that it } \\
\text { defines? }\end{array}$} & $\begin{array}{l}\text { Animal - Agriculture } \\
(2010)\end{array}$ & 'food animals' \\
\hline & & $\begin{array}{l}\text { One Health - Specified } \\
\text { Sectors (0601) }\end{array}$ & $\begin{array}{l}\text { 'surveillance system under One } \\
\text { Health for Hong Kong', 'One Health } \\
\text { surveillance'. Sectors are specified } \\
\text { as shown in the above values. }\end{array}$ \\
\hline Target group & $\begin{array}{l}\text { Is there a specific stakeholder } \\
\text { or group being targeted? }\end{array}$ & Unspecified (00) & $\begin{array}{l}\text { No evidence for specific groups such } \\
\text { as doctors, dentists, farmers, etc. }\end{array}$ \\
\hline \multirow[t]{2}{*}{$\begin{array}{l}\text { Challenge and } \\
\text { subchallenge }\end{array}$} & \multirow{2}{*}{$\begin{array}{l}\text { Does the policy try to } \\
\text { overcome a certain challenge } \\
\text { presented by AMR? If } \\
\text { stated, is there a specific } \\
\text { subchallenge targeted? }\end{array}$} & $\begin{array}{l}\text { Surveillance- } \\
\text { Epidemiology/ } \\
\text { Resistance (0601) }\end{array}$ & $\begin{array}{l}\text { 'development of surveillance on } \\
\text { AMR' }\end{array}$ \\
\hline & & $\begin{array}{l}\text { Surveillance-Use } \\
(0603)\end{array}$ & $\begin{array}{l}\text { 'development of surveillance on(...) } \\
\text { antimicrobial use' }\end{array}$ \\
\hline \multirow[t]{2}{*}{ Building block } & \multirow{2}{*}{$\begin{array}{l}\text { Which component of the } \\
\text { system is the policy utilising or } \\
\text { aiming to improve? }\end{array}$} & Governance (04) & $\begin{array}{l}\text { 'coordination structure', 'working } \\
\text { group', 'steer and oversee' }\end{array}$ \\
\hline & & Information System (06) & $\begin{array}{l}\text { 'Form a network to gather, analyse, } \\
\text { share and link data from multiple } \\
\text { surveillance and monitoring system' }\end{array}$ \\
\hline
\end{tabular}

The resulting list of codes can be seen in figure $2 \mathrm{~B}$.

AMR, antimicrobial resistance; ID, identification number.

which challenges were being addressed. These included policy suggestions to raise awareness of AMR, building an economic case to understand capacity building needs and to strengthen governance in addressing AMR.

In addressing target groups and settings, more than $90 \%$ of the coding did not specify any. Groups which were targeted included veterinarians, prescribers, government, healthcare workers, children, consumers and patients, while settings targeted included laboratories, schools and pharmaceutical companies. About $40 \%$ of the coding noted which policy instruments to be used, with the main instrument being information (22.3\%), followed by regulations $(13.7 \%)$ and economic means through incentives $(4.0 \%$, figure $4 \mathrm{~A}, \mathrm{~B})$. Use of governance was the main building block within $30.9 \%$ of the codes with $30.3 \%$ having no building blocks.

\section{Hong Kong Action Plan}

Within the HKAP, a total of 174 codes were applied to 70 policy statements. The specificity was 2.49 with the largest number of codes applied to a single statement being eight. The average granularity was 6.84 , with the lowest categorical variable with null values being sector and the highest being the target setting. Rather than objectives, 
WHO AMR Global Action Plan (2015)

$\square$ Access $\square$ Conservation $\square$ Containment $\square$ Infection Prevention $\square$ Innovation $₫$ Surveillance $\square$ Unspecified

05: Develop the economic case for sustainable investment that takes account of the needs of all countries, and increase investment in new medicines, diagnostic tools, vaccines and other inventions

04: Optimize the use of antimicrobial medicines in human and animal health

03: Reduce the incidence of infection through effective sanitation, hygiene and infection prevention measures

02: Strengthen the knowledge and evidence based through surveillance and research

01: Improve awareness and

understanding of AMR through effective communication, education and training

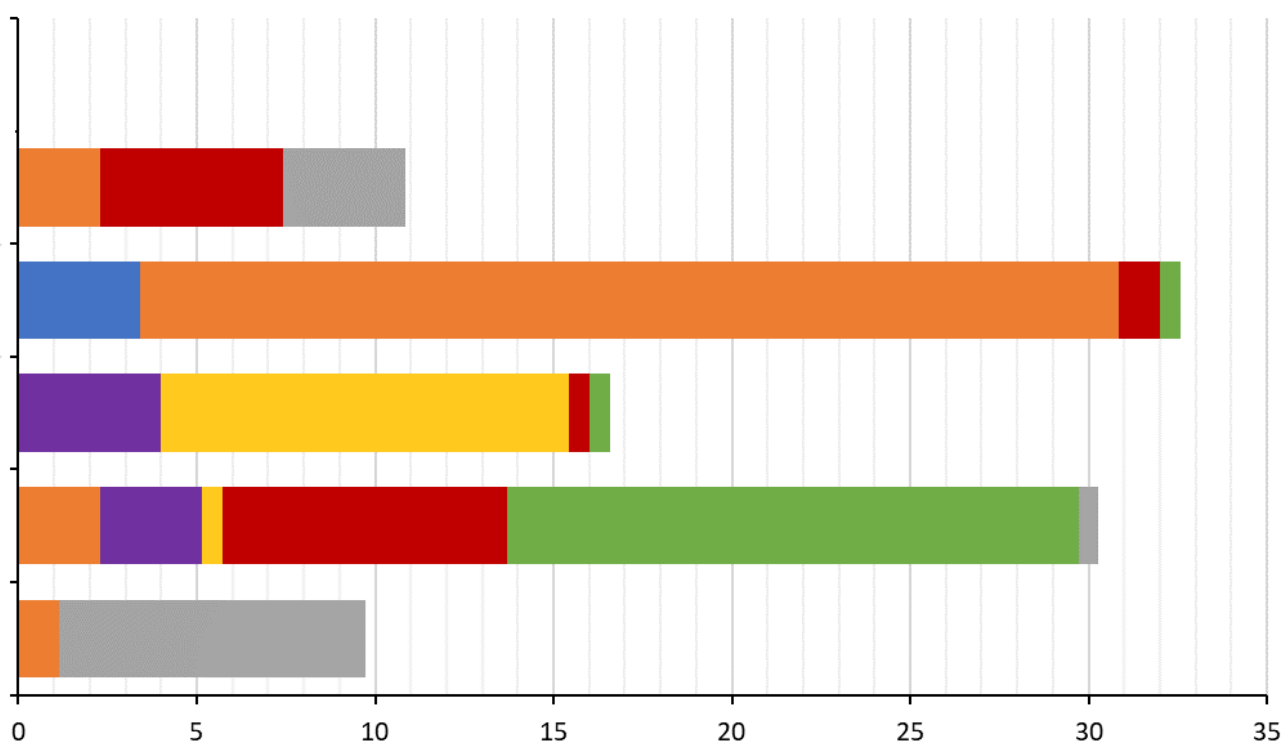

Hong Kong Strategy and Action Plan on AMR (2017 - 2022)

KA6: Strengthen partnerships and foster engagement of relevant stakeholders

KA5: Promote research on AMR

KA2: Optimise use of antimicrobials in human and animals

KA3: Reduce incidence of infection through effective sanitation, hygiene and preventive measures

KA1: Strengthen knowledge through surveillance and research

KA4: Improve awareness and understanding of AMR through effective communication, education and training

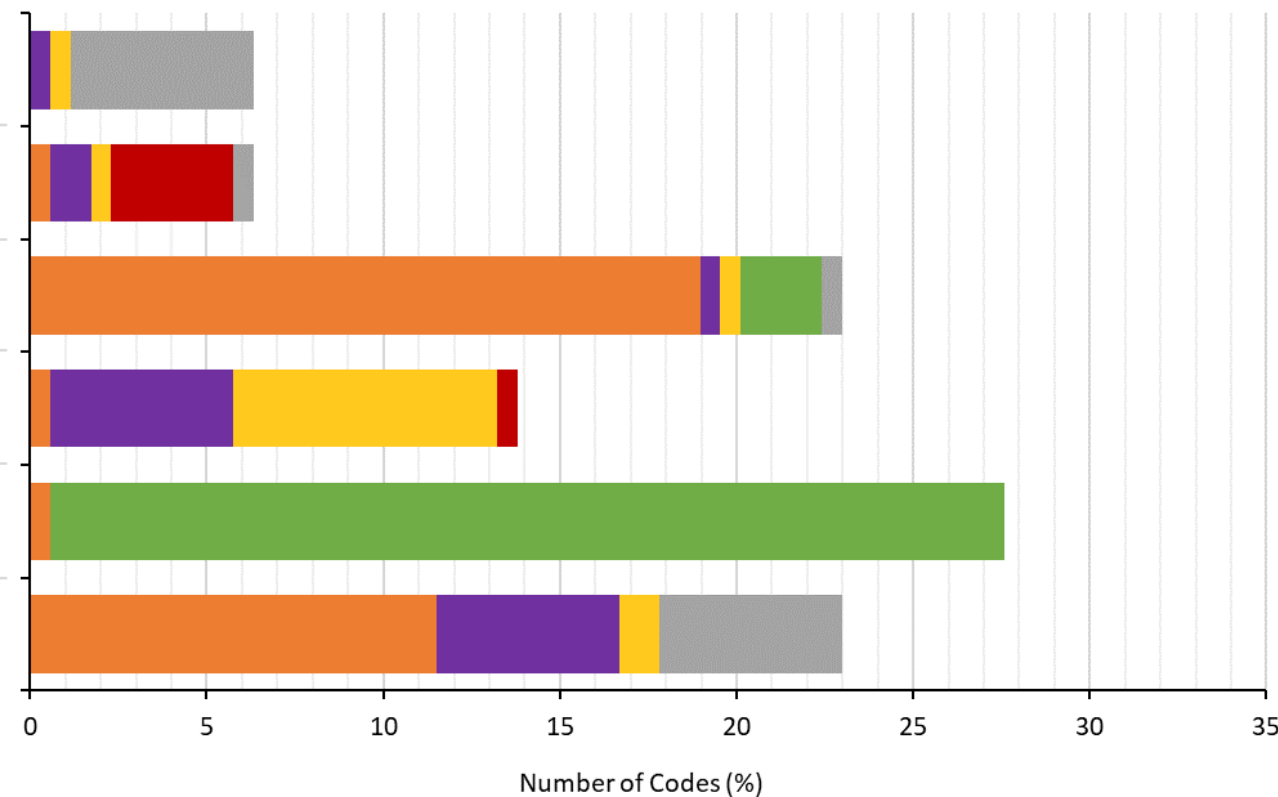

Figure 3 The six challenges of AMR addressed in each of the objectives (GAP) and KAs (HKAP). KAs were arranged in order of the corresponding GAP objectives. Objective 5 in the GAP and KA 5 and 6 in the HKAP did not correspond. Results of coding of statements under 'strategic objectives' and 'framework for action on antimicrobial resistance' was combined for each objective. AMR, antimicrobial resistance; GAP, Global Action Plan; HKAP, Hong Kong AMR Action Plan; KAs, key areas.

the HKAP lists policies under six key areas (KAs). The first four KAs corresponded to objectives 1 to 4 found in the GAP with differing ordering. In place of objective 5 , two new KAs were added for promotion of research and strengthening partnership. The majority of codes were found under KA $1(27.6 \%)$ and the least number of codes were found under both KA 5 and 6 (6.3\%, figure 3$)$.

Policies targeting the human sector made up nearly half of the plan $(42.0 \%)$ closely followed by the animal sector $(40.2 \%)$. There were no policies targeted at the plant sector. About $6.9 \%$ of the coding did not specifically state the sector of target. Similar to the GAP, both conservation $(32.2 \%)$ and surveillance $(29.3 \%)$ were the largest challenges addressed within the AP. There were no policies exploring the improvement of access to antibiotics with innovation being the challenge with the least number of codes $(4.0 \%)$. In total $11.5 \%$ of the coding did not specify any challenges that were being addressed.

More than half of codes did not indicate the target group or target setting. Of those policies that did, the 
WHO AMR Global Action Plan (2015)
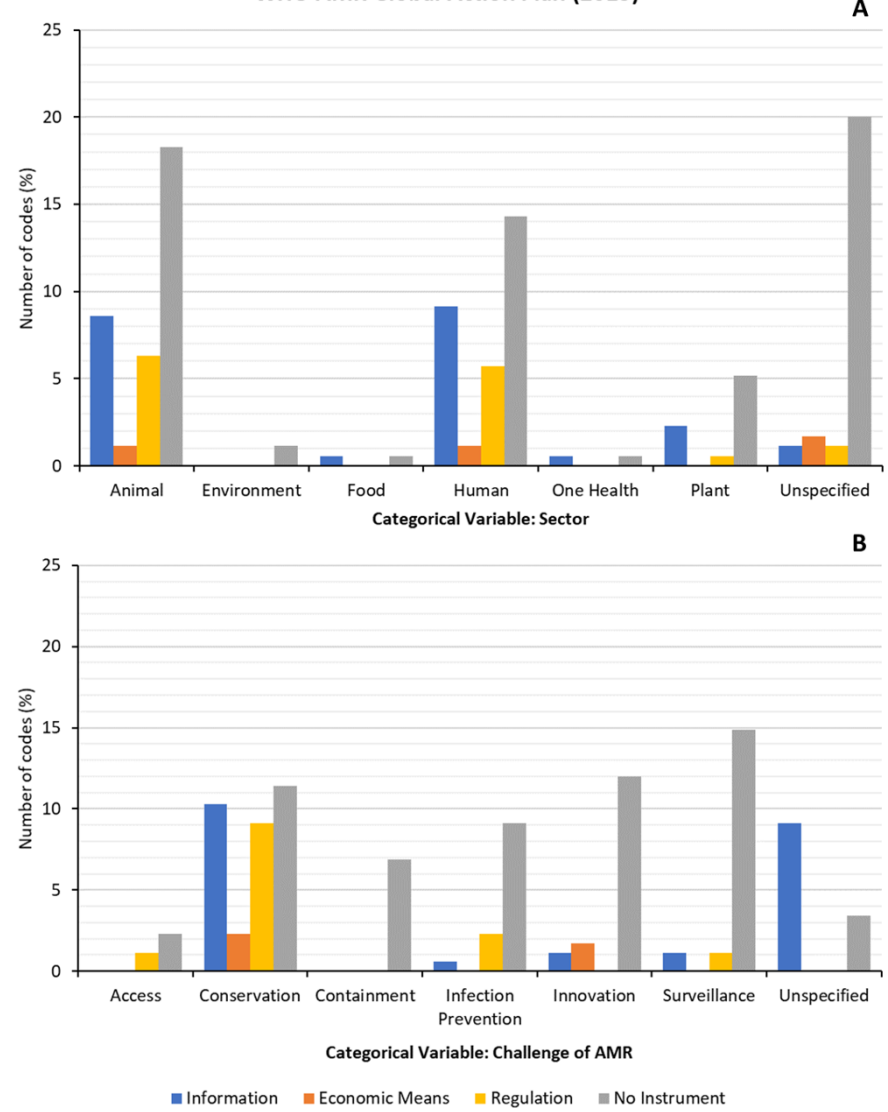

A
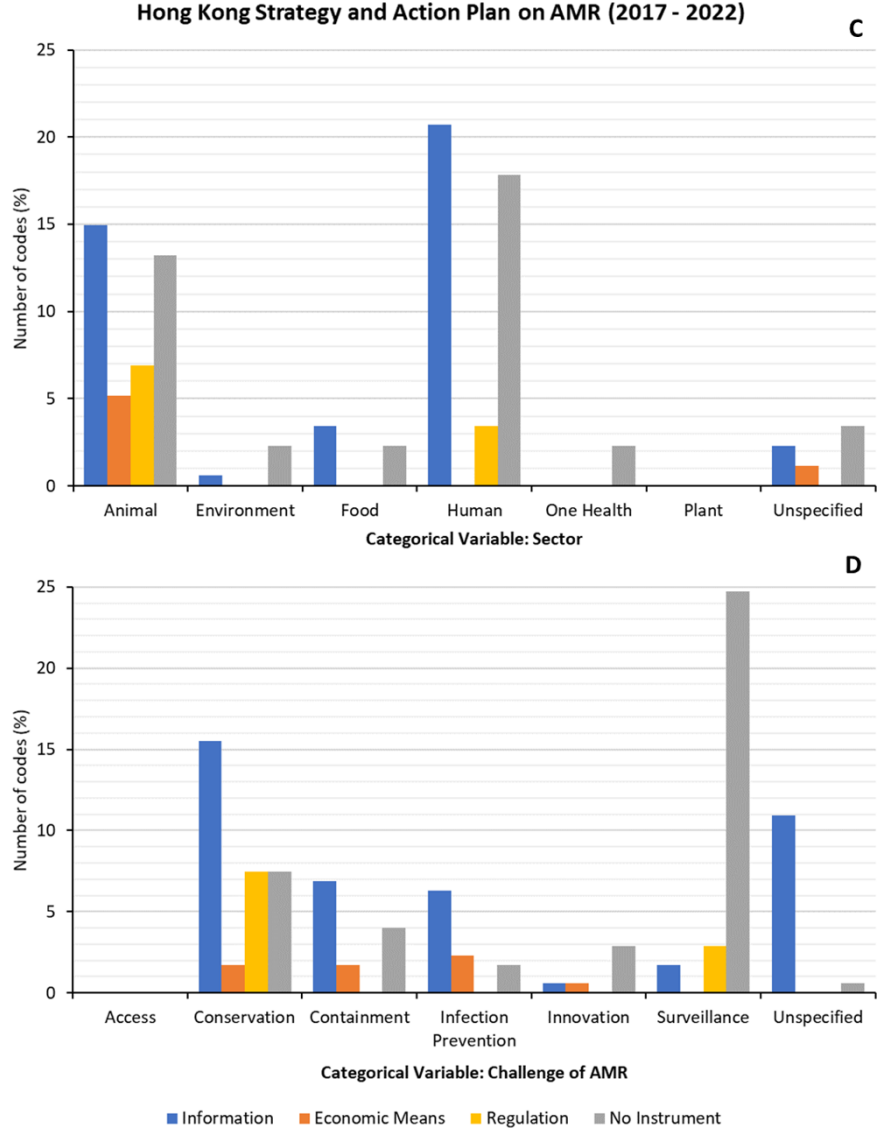

Figure 4 Use of policy instruments in different sectors and challenge of AMR within the GAP and HKAP. AMR, antimicrobial resistance; GAP, Global Action Plan; HKAP, Hong Kong AMR Action Plan.

main targeted groups were farmers, veterinarians and patients with the main targeted settings being farms, hospitals and clinics. Almost $60 \%$ of the codes included one of the policy instruments, with information $(42.0 \%)$ identified as the most used, followed by regulation $(10.3 \%)$ and economic means $(6.3 \%)$. Unlike the GAP, policies in the HKAP does not use incentives through cash but through provision of means in improving AMR in the animal sector (figure 4C). These included providing farms with access to non-government veterinary services, tailor-made disease management plans and helping to source vaccines (figure 4D). Governance was also the main building block (38.5\%) and $23.6 \%$ of codes did not state any.

\section{DISCUSSION}

Formulating AMR policies that are appropriate for addressing the specific determinants of AMR can contribute to an evidence-based and effective approach to combatting the global threat of AMR. Here, we present AMR-PACT as the first framework and methodological approach to analyse past and existing AMR policies within AMR APs through adaptation of an existing framework, the AMR-Intervene. AMR-PACT is intended to provide the basis of the creation of an AMR policy database which can further be linked with the AMR-Intervene database which analyses AMR implementation. With this tool, it is possible to build a database of AMR policies, analyse its contents, implementation instruments and building blocks. The result is a platform that can support analysis of AMR policies and provide insight for policymakers and policy-advisors for formulation of policies.

In our analysis of the GAP and HKAP, we identified both areas in which comprehensive policies exist as well as areas in which significant gaps remain. In both APs, more policies were aimed at the human and veterinary sectors than the environmental and plant sectors. While the GAP lists policies for the horticulture sector, the HKAP does not. Within the registered list of pesticides in HK, medically important antibiotics such as oxytetracycline, streptomycin or aminoglycosides, are not approved for use. ${ }^{36}$ This may explain the lack of policies within this area. For policies in the environmental sector, only two to three policies were identified in either plans highlighting the challenges in formulating actionable policies in this sector, despite the importance of the environmental aspect of AMR. For example, a recent study conducted in HK identified contamination problems through the detection of residues with observed exceedance in landfills possibly due to improper disposal of antimicrobials. ${ }^{37}$ By querying the AMR-PACT database, we were able to identify policies found in other countries' APs which included strengthening wastewater treatment, prevention of environmental contamination by antimicrobials 
or conducting research on methods of decontamination. Countries struggling to formulate policies in these areas could use this database for policy inspiration in other countries facing similar problems. For example, the National Return and Disposal of Unwanted Medicines scheme in Australia provides the public a means to return unused antibiotics for safe disposal through local community pharmacies. ${ }^{38} 39$

In addressing the challenges of AMR, both the GAP and HKAP focus their attention on conserving existing antibiotics and surveying the use of antimicrobials and resistance patterns. However, unlike the GAP, few policies within the HKAP are aimed at innovation and there are no policies to improve access to antibiotics. Due to heavy government subsidisation, HK can offer high-quality healthcare services at minimal charge, thus removing the need for policies to address improvement in access to antibiotics. ${ }^{40}$ In regard to innovation, HK has billiondollar industry in Chinese medicine but none of the largest pharmaceutical companies by revenues. ${ }^{41}$ The lack of policies addressing research and development in the context of AMR is more likely due to the overall absence of a pharmaceutical policy framework within HK. ${ }^{42}$ However, it is also important to note that lack of policies in regards to innovation is not necessarily a shortcoming of a country's policies. In many lower to middleincome countries, for instance, the relevant industrial and research infrastructure does not exist. It is therefore necessary to interpret these findings with the knowledge of the situation regarding the driving forces, pressures, state and impact (DPSIR framework) of AMR within each country. ${ }^{9}$

\section{Strengths and limitations}

To our knowledge, the AMR-PACT is the first framework and methodological approach specifically designed for AMR policy analysis. First, the framework is adapted from existing work looking at interventions. It consists of seven main categorical variables: sectors, target setting, target group, goals, policy process, policy instrument and building block and three subcategorical variables. The overlapping categories and variables provide a way to connect both policies and interventions within a database. Queries can then be conducted to provide further insight into the relationship between AMR policy formulation and implementation. In particular, the ability to calculate both the specificity and granularity of policies will also lend to future research on assessing the relationship between these two parameters and the impact it has on effectiveness and implementation through the linkage with AMR-Intervene database.

The framework's use is not limited to the analysis of NAPs and is equally relevant to other types of policies such as specific legislations introduced by government agencies. Second, our methodological approach helps overcome one of the limitations of content analysis while maintaining the connection between the code, the coded text and the context. Due to the length and structure of the coding string, more variables can be added to each category or subcategorical variable, making this approach flexible and adaptable. As the coding is executed through a numbered string, the framework can be translated to multiple languages as the categories and variables are retained through the same numbering system. This removes the need for large amounts of translation work of policy documents as queries can be performed for output of quantitative data regardless. Moreover, the coding string also provides the ability to analyse the contents of policy documents rather than the document as a whole, providing greater granularity. This is particularly useful for intersectoral issues such as AMR that are being approached from a $\mathrm{OH}$ perspective, where policies aimed at multiple sectors are written in the same policy document.

This methodology can also be applied to non-AMR policy analysis as well, as only the framework and coding string is specific to AMR. It may also be used in conjunction with the AMR governance framework to better understand how policies are linked to governance and vice versa. ${ }^{10}$ Finally, the methodological approach underpins the creation of a database with a complete library of past and current AMR policies that can be easily queried using the values listed in each categorical variable. Paired with a narrative analysis of 'success' stories of certain countries, policymakers, advisors and stakeholders may use this not only for policy innovation but to learn lessons from other governments, institutions or organisations facing similar problems.

However, there are several limitations associated regarding our approach. The main limitation is that formulation of policies is not equal to implementation, which occurs when formulated policies are executed or enforced with frequently significant difference with originally intended aims and objectives of the policymaker. ${ }^{43}$ Additionally, it requires users to categorise thorough understanding of the content of the policies and definitions. Policies are categorised based on literal interpretation by the reader and of what is writing explicitly. Thus, this approach is highly dependent on the clarity of the language used in policy documents. During the coding of the GAP, we encountered difficulties when coding the terms 'animal health and agricultural practice'. As 'agricultural practice' can both be interpreted as both animal agriculture and plant agriculture, coding can be executed in multiple ways. An agreement was made by the team to select values 'animal-unspecified' and 'plant-unspecified' rather than coding twice in the animal sector to reduce the potential over coding over the animal sector. Thus, a single coder is not sufficient enough and to ensure reliability, agreement between multiple coders must be made. Formulated policies within policy documents may not contain the necessary information within the statement themselves. The results only reflect what is written explicitly and the coder should not derive any meaning or assumption, therefore number of policies within the 'unspecified' could 
be overexaggerated. On the other hand, this may reflect the lack of clarity of formulated policies which may affect the variety of interpretation from actors with the role of implementation.

\section{CONCLUSION}

With the recent focus of literature aimed at improvements within AMR policy formulation and implementation, AMR-PACT supports both capacity building and further research. Despite certain limitations, the combination of the framework and methodology not only provides a novel approach to analyse AMR policies but also a way to analyse policy documents while reducing the loss of contextual information. The tool package, including guidance and training on policy coding, definitions and examples along with the overall database structure, represents an easily accessible and executable process for the analysis of AMR policy. A database of past and existing policies related to AMR can support improvement in terms of actionable policies based on problems already identified in other countries and their policy responses. Overall, the database can provide an innovative platform for policymakers, policy-advisors, stakeholders and researchers worldwide. Further exploration is required to establish how existing frameworks can interact and benefit from one another.

Twitter Jasper Littmann @jasperlittmann

Acknowledgements We would like to thank Jessika Hu and the members of the Technical Working Group for their valuable input into this project.

Contributors KF and DW designed the study. All authors contributed to the design of the methodology. $\mathrm{AO}$ and $\mathrm{OC}$ collected the data. DW, KF, AO, OC and HHP analysed and interpreted the data. DW, AO and OC drafted the article. Critical revision of the article was conducted by DW, AO, HHP, JL, NM, NO, XL and KF.

Funding This work was supported with funding from the Policy Innovation and Co-ordination Office of the Government of Hong Kong Special Administrative Region under the Strategic Public Policy Funding Scheme (S2017.A8.005.17S).

Disclaimer The funders had no role in the study design, data collection, data analysis, data interpretation or writing of this publication.

Competing interests None declared.

Patient and public involvement Patients and/or the public were not involved in the design, or conduct, or reporting or dissemination plans of this research.

Patient consent for publication Not required.

Provenance and peer review Not commissioned; externally peer reviewed.

Data availability statement Data, database and codebook are available upon request.

Open access This is an open access article distributed in accordance with the Creative Commons Attribution Non Commercial (CC BY-NC 4.0) license, which permits others to distribute, remix, adapt, build upon this work non-commercially, and license their derivative works on different terms, provided the original work is properly cited, appropriate credit is given, any changes made indicated, and the use is non-commercial. See: http://creativecommons.org/licenses/by-nc/4.0/.

\section{ORCID iDs}

Anju Ogyu http://orcid.org/0000-0002-7055-5509

Olivia Chan http://orcid.org/0000-0003-1684-8105

Jasper Littmann http://orcid.org/0000-0002-6983-8755

Nobuaki Matsunaga http://orcid.org/0000-0002-8637-8252

Norio Ohmagari http://orcid.org/0000-0002-4622-8970

Didier Wernli http://orcid.org/0000-0002-1751-1961

\section{REFERENCES}

1 Mendelson M, Matsoso MP. The world Health organization global action plan for antimicrobial resistance. $S$ Afr Med J 2015;105:325-25.

2 Podolsky SH. The evolving response to antibiotic resistance (1945-2018). Palgrave Commun 2018;4:124.

3 World Health Organization. Global action plan on antimicrobial resistance. Geneva: World Health Organization, 2015.

4 World Health Organization, Food and Agriculture Organization of the United Nations and World Organisation for Animal Health (OIE). Monitoring global progress on addressing antimicrobial resistance: analysis report of the second round of results of AMR country self-assessment survey 2018. Geneva: World Health Organization, Food and Agriculture Organization of the United Nations and World Organisation for Animal Health (OIE), 2018.

5 Klein EY, Van Boeckel TP, Martinez EM, et al. Global increase and geographic convergence in antibiotic consumption between 2000 and 2015. Proc Natl Acad Sci U S A 2018;115:E3463-70.

6 Van Boeckel TP, Pires J, Silvester R, et al. Global trends in antimicrobial resistance in animals in low- and middle-income countries. Science 2019;365:eaaw1944.

7 Dar OA, Hasan R, Schlundt J, et al. Exploring the evidence base for national and regional policy interventions to combat resistance. Lancet 2016;387:285-95.

8 Wernli D, Jørgensen PS, Morel CM, et al. Mapping global policy discourse on antimicrobial resistance. BMJ Glob Health 2017;2:e000378.

9 Wernli D, Jørgensen PS, Harbarth S, et al. Antimicrobial resistance: the complex challenge of measurement to inform policy and the public. PLoS Med 2017;14:e1002378.

10 Anderson M, Schulze K, Cassini A, et al. A governance framework for development and assessment of national action plans on antimicrobial resistance. Lancet Infect Dis 2019;19:e371-84.

11 Kimang'a AN. A situational analysis of antimicrobial drug resistance in Africa: are we losing the battle? Ethiop $J$ Health Sci 2012;22:135-43.

12 Kumar SG, Adithan C, Harish BN, et al. Antimicrobial resistance in India: a review. J Nat Sci Biol Med 2013;4:286.

13 Essack SY, Desta AT, Abotsi RE, et al. Antimicrobial resistance in the WHO African region: current status and roadmap for action. J Public Health 2016;39:8-13.

14 Dumartin C. Prudent use of antimicrobial agents in human medicine: third report on implementation of the Council recommendation. Brussels: European Commission Directorate General for Health and Food Safety, 2015

15 WHO. Monitoring global progress on addressing antimicrobial resistance: analysis report of the second round of results of AMR country self-assessment survey 2018. Monitoring global progress on addressing antimicrobial resistance: analysis report of the second round of results of AMR country self-assessment survey 2018 , 2018.

16 Walt G, Shiffman J, Schneider H, et al. 'Doing' health policy analysis: methodological and conceptual reflections and challenges. Health Policy Plan 2008;23:308-17.

17 Daugbjerg SB, Kahlmeier S, Racioppi F, et al. Promotion of physical activity in the European region: content analysis of 27 national policy documents. J Phys Act Health 2009;6:805-17.

18 Rose S, Spinks N, Canhoto Al. Management research: applying the principles. Routledge, 2014.

19 United Nations. World population policies database. United Nations, 2015.

20 Food and Agriculture Organization. Policy database on employment and decent work in rural areas, 2016.

21 Karakosta C, Flamos A. Managing climate policy information facilitating knowledge transfer to policy makers. Energies 2016;9:454

22 Léger A, Lambraki I, Graells T, et al. AMR-Intervene: a socialecological framework to capture the diversity of actions to tackle antimicrobial resistance from a one health perspective. J Antimicrob Chemother. In Press.

23 Sabatier PA, Weible CM. Theories of the policy process. Westview Press, 2014.

24 Department of Health. UK antimicrobial resistance strategy and action plan. London, UK: Department of Health, 2000.

25 Department of Health, Department of Environment Food \& Rural Affairs. UK five year antimicrobial resistance strategy 2013 to 2018. London, UK: Department of Health, Department of Environment Food \& Rural Affairs, 2013.

26 Government of Japan. National action plan on antimicrobial resistance (AMR) 2016-2020. Tokyo, Japan, 2016. 
27 Government of the Hong Kong Special Administrative Region. Hong Kong strategy and action plan on antimicrobial resistance 20172022. Hong Kong S.A.R, China, 2017.

28 Government of the People's Republic of China. National action plan to contain antimicrobial resistance (2016-2020. Beijing, China: New Hampshire Academy of Family Physicians, 2016.

29 Government of the United Kingdom. Tackling antimicrobial resistance 2019-2024. London, UK: Department of Health and State for Environment, Food and Rural Affairs, 2019.

30 Government of the United Kingdom. Contained and controlled: the UK's 20-year vision for antimicrobial resistance. London, UK, 2019.

31 Interagency Task Force on Antimicrobial Resistance. A public health action plan to combat antimicrobial resistance. Washington DC, USA: Department of Health and Social Care, 2001.

32 Norwegian Ministries. Ministry of Agriculture, Ministry of the Environment, Ministry of Fisheries, et al. Plan of action to combat resistance of antibiotics (2000-2004). Oslo, Norway, 2000.

33 Norwegian Ministries. National strategy for prevention of infections in the health service and antibiotic resistance (2008-2012). Oslo, Norway, 2008.

34 Norwegian Ministries. Ministry of Health and Care Services, Ministry of Fisheries, Ministry of Agriculture and Food, et al. National strategy against antibiotic resistance 2015-2020. Oslo, Norway, 2015: 1-36.
35 White House. National action plan for combating antibiotic-resistant bacteria. Washington DC, USA, 2015.

36 AFCD TGotHKSAR. Registered Pesticides List - Part I and II. Hong Kong SAR: Agriculture FaCD, 2019.

37 Chung SS, Zheng JS, Burket SR, et al. Select antibiotics in leachate from closed and active landfills exceed thresholds for antibiotic resistance development. Environ Int 2018;115:89-96.

38 Tong AYC, Peake BM, Braund R. Disposal practices for unused medications around the world. Environ Int 2011;37:292-8.

39 Wheeler AJ, Spinks J, Bettington E, et al. Evaluation of the National return of unwanted medicines (Rum) program in Australia: a study protocol. J Pharm Policy Pract 2017;10:38.

40 Lee CP. Health care system and pharmacy practice in Hong Kong. Can J Hosp Pharm 2018;71:140-8.

41 Legislative Council. LCQ6: development of pharmaceutical industry in Hong Kong. Hong Kong, 2012.

42 Mercurio B. Drugs, patents and policy: a contextual study of Hong Kong. Cambridge University Press, 2018.

43 Fischer F, Miller GJ. Handbook of public policy analysis: theory, politics, and methods. Routledge, 2017.

44 Jann W, Wegrich K. Theories of the policy cycle. In: Handbook of public policy analysis: theory, politics, and methods. , 2007: 125, 43-62. 